$\begin{array}{ll} & \text { Etnográfica } \\ \text { etnográfica } & \text { Revista do Centro em Rede de Investigação em }\end{array}$

Antropologia

vol. 11 (2) | 2007

Vol. $11(2)$

\title{
Gonçalo Duro dos Santos, A Escola de Antropologia de Coimbra, 1885-1950: O Que Significa Seguir Uma Regra Científica?
}

\section{Patrícia Ferraz de Matos}

\section{(2) OpenEdition}

\section{Journals}

\section{Edição electrónica}

URL: https://journals.openedition.org/etnografica/2066

DOI: 10.4000/etnografica.2066

ISSN: 2182-2891

\section{Editora}

Centro em Rede de Investigação em Antropologia

\section{Edição impressa}

Data de publição: 1 novembro 2007

Paginação: 496-501

ISBN: 0873-6561; E-ISBN 2182-2891

ISSN: 0873-6561

\section{Refêrencia eletrónica}

Patrícia Ferraz de Matos, «Gonçalo Duro dos Santos, A Escola de Antropologia de Coimbra, 1885-1950: 0 Que Significa Seguir Uma Regra Científica?», Etnográfica [Online], vol. 11 (2) | 2007, posto online no dia 27 setembro 2012, consultado o 10 fevereiro 2022. URL: http://journals.openedition.org/etnografica/ 2066 ; DOI: https://doi.org/10.4000/etnografica.2066

\section{Este documento foi criado de forma automática no dia 10 fevereiro 2022.}

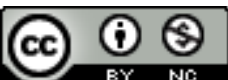

Etnográfica is licensed under a Creative Commons Attribution-NonCommercial 4.0 International License. 


\title{
Gonçalo Duro dos Santos, A Escola de Antropologia de Coimbra, 1885-1950: 0 Que Significa Seguir Uma Regra Científica?
}

\author{
Patrícia Ferraz de Matos
}

\section{REFERÊNCIA}

Gonçalo Duro dos Santos, A Escola de Antropologia de Coimbra, 1885-1950: O Que Significa Seguir Uma Regra Científica?, Lisboa, Imprensa de Ciências Sociais, 2005, 234 páginas.

1 A Escola de Antropologia de Coimbra, 1885-1950 é o primeiro livro de Gonçalo Duro dos Santos, licenciado em antropologia pela Universidade de Coimbra e doutorado em antropologia pelo ISCTE. O livro constitui um importante contributo para a história da antropologia portuguesa e debruça-se, especificamente, sobre a escola de antropologia de Coimbra, desde a sua fundação, em finais do século XIX, por Bernardino Machado, que se inspirou sobretudo nos trabalhos do médico e antropólogo Ferraz de Macedo, até meados do século XX, altura em que Eusébio Tamagnini vem contribuir para a sua consolidação e afirmação. Este estudo ultrapassa, porém, o estatuto de uma crónica sobre a história desta escola. Para além da perspectiva crítica do autor, o trabalho contém elementos fundamentais, não só contextuais, mas também biográficos, acerca dos actores que a ela estiveram ligados e das suas agências. No que a esta escola especificamente concerne existiam até esta publicação os seguintes trabalhos: a edição comemorativa Cem Anos de Antropologia em Coimbra, 1885-1985, Coimbra, MLAUC (1985); e a dissertação realizada no âmbito do seminário de investigação da licenciatura em antropologia de Duro dos Santos (1996). Podemos ainda referir dois textos citados no livro, um de Areia et al (1991) e outro de Gouveia (1978), ambos sobre o Museu e 
Laboratório Antropológico da Universidade de Coimbra. Tal escassez parece justificar desde logo esta publicação e a necessidade de trazer à luz do dia outros contributos.

2 O livro divide-se em dois capítulos principais (o 2 e o 3) e tem uma introdução que aparece como o capítulo 1. Não possui uma conclusão intitulada como tal, mas a parte final do terceiro capítulo apresenta-nos as conclusões do trabalho. A complementar a exposição existem 69 notas de fim de texto, a maioria com elementos biográficos. Para o autor, este estudo permite-nos reflectir sobre uma questão central na antropologia e sociologia da ciência que pode ser levantada pela pergunta de inspiração wittgensteiniana: “o que significa seguir uma regra científica?" Esta pergunta, que dá o subtítulo ao livro, permite formular uma outra questão: "o que significa seguir uma regra política?" E isto porque o principal dirigente da escola de antropologia de Coimbra, Eusébio Tamagnini, juntou ao seu papel de "agente científico" o de "agente político oficial" do Estado Novo, o que denota a estreita ligação entre o campo científico e o campo político que então existia (p. 20). Também a figura de Bernardino Machado surge como um exemplo de que "a separação formal entre o campo político e o campo científico" não era "uma realidade nem legal nem prática" (p. 103). É o próprio Tamagnini a considerar que a ciência "tem de servir os interesses nacionais" e a política tem "de se fundar sobre o conhecimento biológico do agregado nacional" (p. 171). Esta proximidade, ou mesmo infiltração de domínios diferentes, suscitou o levantamento de questões às quais o autor pretendeu responder. O livro surge na sequência da dissertação de licenciatura do autor, que contém uma análise discursiva da produção científica de Tamagnini, e resulta da reflexão continuada (sete anos) sobre as questões enunciadas e outras que lhes são anexas e da revisão crítica do material empírico sobre o qual trabalhou entre 1995 e 1996 em Coimbra, num departamento onde existe uma "conjugação (hoje preciosa) do ensino e investigação da antropologia biológica com o ensino e investigação da antropologia social" (p. 20-21). No que respeita aos aspectos metodológicos, o autor, que se considera um "trabalhador do detalhe empírico genealógico" (p. 138), revela que optou "por uma escrita mais sugestiva do que demonstrativa para assim facilitar o trabalho de leitura", na qual a informação contextualizante surge na nota (p. 21). Embora a contextualização vá muitas vezes para a "nota", é bem perceptível o seu cuidado em situar histórica e cientificamente o trabalho no texto principal. Como refere Miguel Vale de Almeida no prefácio, Duro dos Santos situa-se "nos debates contemporâneos que discutem a necessidade de pôr em diálogo o desconstrutivismo com um certo regresso às contextualizações históricas $\mathrm{e}$ sociológicas" (p. 14).

3 O contexto aqui tratado inclui não só o período de institucionalização da escola de antropologia de Coimbra, mas também o da escola de antropologia do Porto, na qual se destaca a figura de Mendes Correia, e a sua proximidade académica e política com Tamagnini, embora saibamos que essa proximidade não existia ao nível pessoal, além de que entre "Coimbra" e o "Porto" existiam rivalidades. Por outro lado, neste período assistiu-se a um grande desenvolvimento das práticas científicas antropológicas, não só ao nível nacional, mas também internacional e, nesse sentido, talvez pudesse ter existido no texto mais espaço para dar conta, de uma forma comparativa, das práticas antropológicas contemporâneas às da escola de antropologia de Coimbra, mas produzidas no estrangeiro, e do porquê de algumas semelhanças e/ ou diferenças. Talvez esse esforço comparativo nos pudesse esclarecer melhor sobre a razão por que em determinadas alturas em Portugal se produziu uma antropologia e não outra e por 
que alguns portugueses que escrevem sobre a história da antropologia do seu país têm omitido ou ofuscado essa antropologia. Apenas alguns autores reconhecem a existência de uma escola de antropologia ligada a Coimbra e de outra ligada ao Porto, assim como o legado deixado pelos seus mentores e pelos seus discípulos. Além disso, às figuras que a estas escolas estiveram ligadas nem sempre é reconhecida cientificidade.

$\mathrm{O}$ autor traz a lume as versões da história da antropologia portuguesa de autores como Freitas Branco, João de Pina-Cabral ou João Leal. Para Duro dos Santos, existe "uma certa tendência amnésica no estado--da-arte do estudo da história da antropologia em Portugal (...) para projectar teleologicamente no material histórico em questão a (...) separação hierárquica pós-durkheimiana ou pós-boasiana entre o 'estudo dos factos sociais / culturais' e o 'estudo dos factos naturais' e para (...) não apenas não dar conta da existência desde os finais do século XIX de todo um conjunto de importantes reflexões antropológicas evolucionistas na variante naturalista, mas também reduzir o avant-gardismo na história da actividade antropológica em Portugal a trabalhos desenvolvidos na sua variante historicista". Segundo o autor, o trabalho de Jorge Dias no desenvolvimento do "estudo empírico de orientação tanto culturalista quanto nacionalista de comunidades rurais portuguesas (e em menor grau de comunidades coloniais)", a partir da década de 50, é normalmente considerado renovador uma vez que se dissocia "de um grupo de trabalho no Porto (...) que vinha desenvolvendo estudos sistemáticos dos tipos 'físicos/ biológicos' e 'culturais/ sociais' tanto de populações nacionais como de populações coloniais". E terão sido as limitações teóricas de J. Dias, assim como "a dimensão explicitamente nacionalista e/ou colonialista de muitos dos seus projectos etnográficos" que levaram a que antropólogos como PinaCabral representassem "a antropologia em Portugal durante a primeira metade do século XX nos termos de um acentuado 'anacronismo científico"'. Para Duro dos Santos, em Portugal a história da variante naturalista das reflexões antropológicas não é separável da história da variante historicista e o que "torna um empreendimento científico interessante e renovador é a qualidade dos seus dados empíricos e da sua argumentação vistos no espaço dos possíveis (...) do contexto histórico-social do campo científico" (pp. 80-84).

5 O reconhecimento da importância do "estudo dos factos naturais" para esta análise é um dos méritos do livro que se aproxima assim do tema de trabalho do volume 9 da colecção History of Anthropology, intitulado Excluded Ancestors, Inventible Traditions, Essays Toward a More Inclusive History of Anthropology (2000) e vem contribuir também para uma história da antropologia mais inclusiva, na qual são lembrados alguns "ancestrais" da disciplina que foram caindo no esquecimento. Contudo, considero que se as análises da história da antropologia portuguesa têm omitido factos, figuras e episódios por parte dos estudiosos, não é por desconhecimento dos mesmos, mas sim por opção ou por uma incipiente motivação para tratar questões tornadas tabu no período pós-segunda guerra mundial dando lugar a outras prioridades. A essa opção não terá sido alheia a repugnância ao racismo inerente a formulações que brotaram tanto da escola antropológica de Coimbra, como da escola antropológica do Porto, assim como o envolvimento político de algumas figuras dessas escolas com o regime do Estado Novo. Por outro lado, o relativo silenciamento dessa antropologia por parte dos autores mais recentes, atraídos apenas pela antropologia social e cultural, poderá dever-se também à sua ausência de formação na área da antropologia biológica e à influência do paradigma de base durkheiminiana de que os factos sociais têm explicações sociais (e não extrasociais, naturais) e que, da mesma forma, a antropologia física, ao contrário do que 
aspiravam alguns dos seus praticantes, não poderia também explicar factos sociais ou culturais.

6 A introdução do livro dá-nos alguns dos apetrechos teóricos que o autor vai utilizar na sua análise. Inspirado em Bourdieu, Duro dos Santos faz algumas incursões teóricas acerca do que é o "jogo" e em que "campos" surge (p. 39). Os jogadores vão ser os actores sociais cujo percurso e interacção o autor vai analisar. Na dissertação de licenciatura o autor já tinha verificado existir uma "colaboração explícita ou implícita de uma grande parte das elites académicas e universitárias com o então emergente regime totalitário do Estado Novo" e a "colaboração oficial e activa de Eusébio Tamagnini e da escola de antropologia de Coimbra" com esse regime. Tal verificação levou o autor a estabelecer um "paralelo entre a história da antropologia em Coimbra e a história da antropologia de inspiração naturalista no contexto germânico" (p. 33). Contudo, no que às pessoas ligadas à escola de antropologia de Coimbra concerne, não deveremos fazer generalizações abusivas. Se é certo que Tamagnini esteve ligado ao regime de Salazar, tendo sido, por exemplo, ministro da Instrução Pública (1934-1936), já Bernardino Machado, por exemplo, não teve esse envolvimento e foi uma das personalidades que mais criticou o Acto Colonial e as discriminações que este continha. Por outro lado, e como observa o autor, embora encontremos na Alemanha dos anos 30 e 40 a "elaboração científica de uma grandiosa história natural da 'população alemã" e a "planificação científica de um gigantesco programa político eugénico (...) visando a eliminação positiva e negativa de todas as populações nacionais medicamente diagnosticadas como 'deficientes', 'retardadas', ou 'racialmente degeneradas', já em Portugal essa colaboração "passaria de forma análoga pela elaboração científica de uma grandiosa história natural da 'população portuguesa', mas acabaria por se ficar pela planificação científica dos alicerces de um programa político-pedagógico de higiene racial e sexual" (p. 33-34). Tal deveu-se também à influência da "ética social" da "elite dirigente católica nacional" (p. 169).

7 O capítulo 2 trata "o processo histórico de autonomização do campo da antropologia em Portugal no contexto europeu" e aborda "as reflexões antropológicas evolucionistas na Europa" com "uma variante naturalista" ou com "uma variante historicista". Segundo o autor, uma vez que os "desenvolvimentos científicos em Coimbra (...) são largamente empreendidos por uma importação formal de modelos analíticos desenvolvidos em contextos nacionais e institucionais de outras nações europeias", é necessário "tomar em conta (...) a forma como se processa a sua selecção e a sua recontextualização" na produção científica portuguesa (p. 55). Para explicar as variantes das reflexões antropológicas, o autor inspira-se em Foucault, que descreve "a emergência na Inglaterra e na França do século XVII (...) de uma forma discursiva no domínio da história na qual a guerra e os seus diferentes aspectos (...) começam a ser utilizados como um princípio de análise da história e (...) das relações sociais" (p. 56). Para Foucault é devido a este princípio que a partir do século XVIII vão desenvolver-se na Europa "dois tipos de descodificações (déchiffrement) evolucionistas da história, a luta social de classes/civilizações e o confronto biológico de raças / espécies / populações, igualmente assentes na postulação de uma mecânica de evolução natural pela sobrevivência / hegemonia das populações (naturais e sociais) mais aptas" (p. 56). $\mathrm{Na}$ opinião de Duro dos Santos, "o conteúdo desta oposição discursiva (...) será gradualmente reproduzido, no domínio das reflexões antropológicas propriamente 
ditas (...) nos termos de uma oposição discursiva entre uma variante historicista e uma variante naturalista" (pp. 56-57).

8 A partir da "variante mais historicista" ter-se-á desenvolvido "uma tradição científica de estudo dos usos e costumes das populações ditas populares / arcaicas" e "grandes esquemas antropológicos sobre a evolução da humanidade à escala universal" (p. 61). Além disso, será do lado desta variante mais historicista "que se começará a empreender na primeira metade do século XX a crítica científica ao próprio discurso evolucionista (...) e (...) ao determinismo naturalista e biológico na interpretação da evolução da humanidade". O autor refere-se aqui à "crítica de avant-garde de antropólogos e outros cientistas que - seguindo Franz Boas (1858--1942), nos EUA, e Émile Durkheim (1858--1917), na Europa - procuram demonstrar, por um lado, a igualdade fundamental de todas as populações humanas e lançar, por outro lado, a separação institucional entre o estudo dos factos 'naturais' e o estudo dos factos 'sociais"' (p. 62). Por seu turno, foi a partir da variante mais naturalista que se formaram na segunda metade do século XIX áreas como a antropologia geral, a arqueologia pré-histórica, a paleontologia humana, a antropologia criminal e a antropologia física. Esta variante desenvolveu-se inicialmente nos contextos francês, italiano e alemão e foi nela que se filiou a actividade antropológica em Coimbra. De acordo com a variante mais naturalista, "a comparação entre diferentes populações humanas é feita em função de um (...) cânone anatómico - o homem branco e europeu de elite" (p. 67). No livro surgem também exemplos das tentativas de Tamagnini para provar que os portugueses eram representantes dessa elite.

9 O capítulo 3, o mais longo, com mais material empírico, mas também o mais descritivo, sobretudo no que diz respeito aos elementos biográficos, trata "o processo histórico de emergência e consolidação da escola de antropologia de Coimbra". Nele enfatiza-se de novo a defesa de uma complementaridade do estudo dos factos culturais/ sociais e do estudo dos factos naturais, tanto no programa de "antropologia geral" de Paul Broca, como depois para Bernardino Machado e mais tarde para Tamagnini. No entanto, e apesar das grandes colecções etnográficas do Museu de Antropologia de Coimbra, houve desde o início uma maior negligência relativamente aos estudos na variante social / cultural, tanto no ensino como na investigação (pp. 110-112). Além disso, e apesar das semelhanças com algumas tradições naturalistas, como é o caso da escola de Paris, houve, segundo o autor, uma diferença fundamental entre elas: "a escala de comparação" (p. 118). É que em Coimbra, em vez de se ter impulsionado um estudo da “'história natural do homem' à escala universal", como se fez em Paris, promoveu-se uma '"história natural do homem' à escala familiar do 'mundo português' na moldura da Europa” (p. 118). Esse esforço procurava evidenciar que, embora pudesse existir algum contacto dos portugueses da metrópole com as colónias, podendo vir a resultar desses contactos futuras degenerações, os portugueses continuavam a demonstrar características muito próprias no âmbito das suas características físicas, que eram exemplificativas de que o português (da metrópole) era um representante das "raças" superiores europeias. O problema da degeneração (física e cultural) é tratado, por exemplo, na primeira dissertação de Tamagnini a propósito dos "indígenas crioulos" de São Tomé que, tal como as crianças, deveriam ser orientados pedagogicamente (p. 170). Para Duro dos Santos, "a actividade antropológica em Coimbra (...) revela-se paroquial (...) ao nível da pequenez da escala comparativa dos seus discursos", preterindo um projecto mais universal de humanidade em favor de um projecto mais nacionalista de humanidade (p. 119). Tal como em outros países, Comte foi influente em Portugal. 
Porém, para Duro dos Santos houve um processo de "recontextualização do positivismo francês na antropologia deste período em Portugal", no qual "o evolucionismo pessimista mas universalista" de Comte foi "largamente reconfigurado na forma de um evolucionismo pessimista feito a priori à escala nacional". Foi este nacionalismo que isolou "a 'população portuguesa', o 'mundo português', o 'império português', da 'humanidade universal' com vista à síntese de uma 'história natural do homem português"' (p. 157).

O livro debruça-se sobretudo na primeira metade do século XX, aborda o período que a precede, mas não o seguinte, circunscrevendo o discurso a 1950. Todavia, é pena o autor não ter abordado as mudanças que se registaram logo após 1945. Gostaríamos de saber até que ponto terão sido os protagonistas da escola de antropologia de Coimbra sensíveis a estas alterações. Por outro lado, embora refira alguns, o autor dá pouca atenção aos trabalhos produzidos no âmbito colonial e as suas relações com outros trabalhos, partindo quase do pressuposto do "não desenvolvimento em Portugal de uma tradição colonial" (p. 159) por oposição ao desenvolvimento de estudos que enfatizavam a pureza e a originalidade da população portuguesa. Tais abordagens não deverão, em meu entender, ser vistas como distintas, mas como complementares ou até consequentes, pois é porque inicialmente o "outro colonial" foi visto como pertencendo a um mundo distinto do mundo do sujeito do discurso que foi necessário reforçar as análises no sentido de demonstrar a distância biológica e cultural desse sujeito relativamente ao mundo colonial. Dos aspectos menos bem conseguidos do livro assinalamos o estilo de escrita e alguns lapsos. Para além de escrever frequentemente com frases longas, o autor intercala por vezes o seu raciocínio com pormenores entre travessões que podem chegar a ocupar 17 linhas (p. 59), repete as mesmas expressões ou ideias em locais distintos quando fala de Boas e Durkheim (pp. 62, 65) e rediz o que tinha referido numa nota anterior (p. 93). Além disso, algumas notas de fim de texto são longas, repetem elementos do texto principal ou de notas anteriores. Um outro lapso é a data de falecimento de Mendes Correia que é 1960 e não 1969 (pp. 30, 175). Não obstante, esta obra deverá ser de leitura obrigatória para todos os que queiram saber mais sobre alguns dos precursores da antropologia tantas vezes esquecidos ou ignorados.

\section{AUTORES}

\section{PATRÍCIA FERRAZ DE MATOS}

Doutoranda do Instituto de Ciências Sociais da Universidade de Lisboa e bolseira da Fundação para a Ciência e a Tecnologia 